\title{
A thermal model of the wet grinding process
}

\author{
Y.S. Liao ${ }^{\mathrm{a}, *}$, S.Y. Luo ${ }^{\mathrm{b}}$, T.H. Yang ${ }^{\mathrm{a}}$ \\ ${ }^{a}$ Department of Mechanical Engineering, National Taiwan University, Taipei, Taiwan, ROC \\ ${ }^{\mathrm{b}}$ Department of Mechanical Engineering, Huafan University, Shihtin, Taipei, Taiwan, ROC
}

Received 9 September 1998

\begin{abstract}
A thermal model of the wet grinding process is presented. The thermal effect of the grain-workpiece interface and the shear plane between the workpiece and the chip is taken into account. By taking all of the parameters needed in the model from the experimental results, the temperature of the workpiece surface in the grinding zone can be predicted. It is shown that the flow rate of the grinding fluid under general grinding conditions is sufficient to cover the thermal boundary layer of the coolant in the grinding zone. The predicted workpiece surface temperatures have been compared to experimental data for some grinding conditions. Good agreement is obtained except for the creep-feed grinding process, when water-based grinding fluid is used. The differences between the theoretical values and experimental results are attributed to constant thermal properties, and neglect of transverse conduction in the development of the thermal model. (C) 2000 Published by Elsevier Science S.A. All rights reserved.
\end{abstract}

Keywords: Thermal model; Wet grinding; Temperature; Grain/workpiece interface; Shear plane

\section{Nomenclature}

A

$b$

$b^{\prime}$

$c_{p}$

$D$

$h$

$k$

$l$

$n$

$\dot{Q}_{\text {c,useful }}$ useful coolant flow rate through the grinding zone

$q^{\prime \prime} \quad$ heat flux

$r \quad$ ratio of average chip width and average chip thickness $\left(r=b^{\prime} / t_{\mathrm{c}}\right)$

$r_{0} \quad$ radius of the moving heat source

$T$ temperature

$t \quad$ time

$t_{\mathrm{c}} \quad$ average undeformed chip thickness

$u_{\mathrm{sh}} \quad$ specific chip formation energy
$V \quad$ velocity

$x \quad$ coordinate in the direction of wheel motion

$X \quad$ dimensionless $x(X=x V / \alpha)$

$z \quad$ coordinate in the normal direction of wheel motion

$Z \quad$ dimensionless $z(Z=z V / \alpha)$

$\alpha \quad$ thermal diffusivity $\left(\alpha=k / \rho c_{p}\right)$

$\Theta \quad$ dimensionless temperature $\left(\Theta=\left(T-T_{\mathrm{i}}\right) /\left(q^{\prime \prime} /\right.\right.$ $\left.\rho c_{p} V\right)$ )

$\theta$ temperature rise relative to the inlet temperature $\left(\theta=T-T_{\mathrm{i}}\right)$

$\rho$ density

$\delta \quad$ boundary thickness or thickness of the fluid layer on the grinding zone

$\phi \quad$ shear angle

$\phi_{\mathrm{s}} \quad$ effective wheel porosity

$\phi_{\mathrm{b}} \quad$ bulk wheel porosity

$\Phi \quad$ dimensionless effective wheel porosity $=\phi_{\mathrm{s}} / \phi_{\mathrm{b}}$

\footnotetext{
${ }^{*}$ Corresponding author. Tel.: +886-2-2362-6431; fax: +886-2-2363-1955.
}

\begin{tabular}{ll}
\multicolumn{2}{l}{ Subscripts } \\
c & chip \\
f & fluid \\
g & grain \\
i & inlet \\
s & surface
\end{tabular}




$\begin{array}{ll}\text { sh } & \begin{array}{l}\text { shear plane } \\ \text { thermal boundary }\end{array} \\ \mathrm{w} & \text { workpiece } \\ \mathrm{wb} & \text { workpiece background } \\ \mathrm{wf} & \text { grain/workpiece interface } \\ \mathrm{wg} & \text { workpiece under grain } \\ \mathrm{ws} & \text { workpiece and wheel }\end{array}$

\section{Introduction}

In the metalworking industry, the grinding process is a very important method of producing a precision part. For ductile materials, the specific energy generated during a grinding process is generally very high, and is mostly dissipated as heat in the wheel-workpiece contact [1]. This heat would cause the workpiece and the wheel temperature to rise. An elevated temperature can cause the workpiece to produce thermal damage such as workpiece burning, phase transformation, residual stresses, cracks, etc. These would lead the fatigue strength of ground workpieces to reduce [2]. In addition, high temperature during grinding would lead the abrasives and the bond of the wheel to weaken or degrade, which will accelerate wheel wear, and worsen the grinding performance. Grinding fluids are typically used to avoid these undesirable effects. However, Yasui and Tsukuda [3] and Ohishi and Furukawa [4] indicated that when the surface temperature reached a value slightly in excess of $100^{\circ} \mathrm{C}$ for water-based grinding fluid and $300^{\circ} \mathrm{C}$ for oil-based fluid, the temperature rose rapidly, accompanied by thermal damage to the workpiece surface.

A review of the literature reveals that considerable research effort has been devoted to the thermal aspects of grinding. Early study by Jaeger [5], Outwater and Shaw [1], Hahn [6], Des Ruisseaux and Zerkle [7], and Malkin [8,9] concentrated on predicting the workpiece surface temperatures in dry grinding. In wet grinding, Des Ruisseaux and Zerkle [10] modeled convective cooling with a constant convection coefficient $h$ over the entire surface. They indicated that for sufficiently large values of the dimensionless convection coefficient $H=2 \alpha_{\mathrm{w}} h / k_{\mathrm{w}} V_{\mathrm{w}}$, convection can substantially reduce the temperature. Lavine [11] developed a model with convective heat transfer between the workpiece, the wheel, and the grinding fluid. He stated that when the thermal properties of the materials used were adjusted appropriately, the predicted workpiece surface temperature could match the experimental data. Lavine and Jen [12,13] developed models that coupled heat transfer to an abrasive grain, the workpiece, and the fluid for heat generated at the grain-workpiece interface in grinding. They indicated that the prediction of the workpiece background temperature compared with experimental data for a grain-workpiece contact area of $1 \%$ was reasonably good. However, the grain-workpiece contact area varies with the wheel type, and the heat source of the model only takes that into account at the grain-workpiece interface. In addition, the dimen-

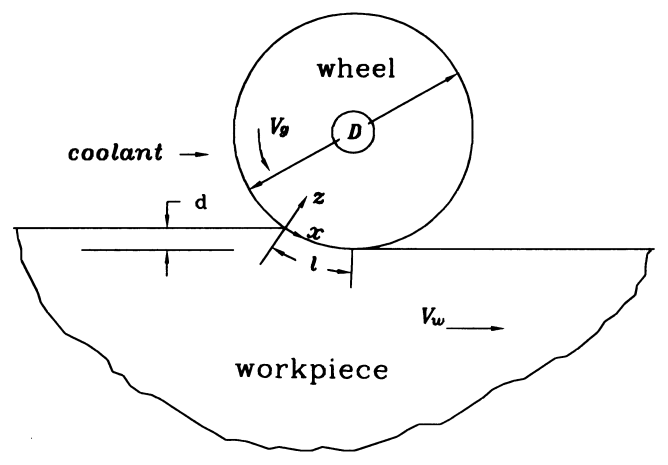

Fig. 1. The geometry of the wheel-workpiece contact in a down-grinding process.

sionless workpiece background temperature depended on the thermal properties of the materials, the operating conditions, and the wheel geometry, and its level was found to depend strongly on the fluid type and the abrasive grain type. It also depended strongly on the ratio between the wheel velocity and the workpiece velocity.

In this paper, the analysis of heat transfer in the wet grinding process considers two heat sources, one being generated at the grain-workpiece interface and the other at the shear plane between the workpiece and the chip. In addition, the fraction of grain-workpiece contact area in grinding is also investigated.

\section{Thermal analysis}

The geometry of the wheel-workpiece contact in a downgrinding process is shown in Fig. 1. The grinding zone is the region of length $l(=\sqrt{D d})$ and width $b$ (into the page) over which the wheel contacts the workpiece. The heat sources during grinding are from three locations: the abrasive grain/ workpiece interface; the abrasive grain/chip interface; and the shear plane between the workpiece and the chip (see Fig. 2). The two mechanisms of heat generated are friction (at the grain/workpiece and grain/chip interface) and plastic deformation (at the shear plane and at the grain/ workpiece interface due to planning). The heat generated in

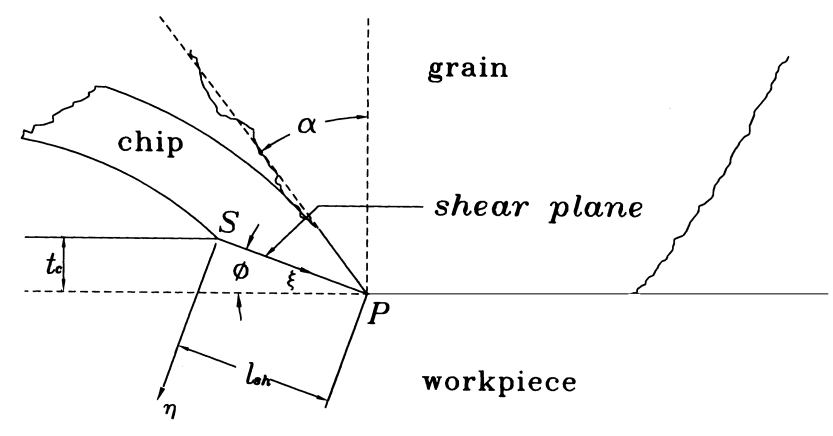

Fig. 2. A schematic illustration of chip formation. 


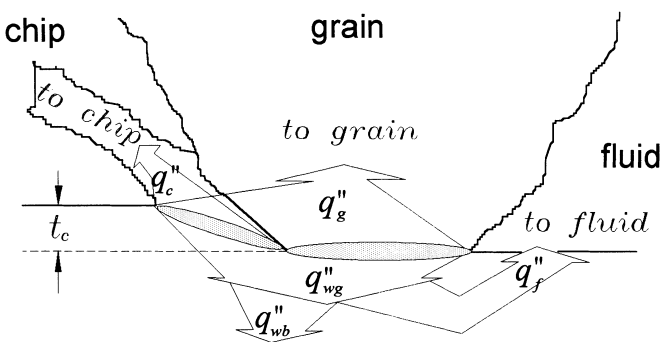

to background

workpiece

Fig. 3. Heat-transfer path.

the grinding zone during wet grinding is transferred into the chip, the grinding fluid, the wheel, and the workpiece.

In the model, heat will be assumed to be generated at the shear plane and at the grain/workpiece interface, and its value is $q_{\mathrm{total}}^{\prime \prime}=q_{\mathrm{sh}}^{\prime \prime}+q_{\mathrm{wf}}^{\prime \prime}$, where $q_{\mathrm{sh}}^{\prime \prime}$ is the rate at which heat is generated at the shear plane (per unit area) and $q_{\mathrm{wf}}^{\prime \prime}$ is the heat flux generated at the grain/workpiece interface (refer Fig. 3). The heat, $q_{\mathrm{sh}}^{\prime \prime}$, is conducted instantaneously into either the chip, the workpiece, or the wheel. Thus, $q_{\mathrm{sh}}^{\prime \prime}=q_{\mathrm{c}}^{\prime \prime}+q_{\mathrm{ws}}^{\prime \prime}$, where $q_{\mathrm{c}}^{\prime \prime}$ is the heat flux into the chip and $q_{\mathrm{ws}}{ }^{\prime \prime}$ is the heat flux into the workpiece and the wheel. The heat flux, $q_{\mathrm{wf}}^{\prime \prime}$, can be expressed as $q_{\mathrm{wf}}^{\prime \prime}=q_{\mathrm{total}}^{\prime \prime}-q_{\mathrm{c}}^{\prime \prime}$ because the heat flux $q_{\mathrm{ws}}^{\prime \prime}$ is considered as a part of the heat source at the grain/workpiece interface. This heat will be conducted into the workpiece or the wheel. It can be expressed as follows: $q_{\mathrm{wf}}^{\prime \prime}=q_{\mathrm{g}}^{\prime \prime}+q_{\mathrm{wg}}^{\prime \prime}$, where $q_{\mathrm{g}}^{\prime \prime}$ is the heat flux into the grain and $q_{\mathrm{wg}}^{\prime \prime}$ is the heat flux into the workpiece at the grain location. Some of the heat flux $q_{\mathrm{wg}}^{\prime \prime}$ will remain in the workpiece and some is removed by convection to the fluid. This can be expressed as $q_{\mathrm{wg}}^{\prime \prime}=q_{\mathrm{wb}}^{\prime \prime}+q_{\mathrm{f}}^{\prime \prime}$, where $q_{\mathrm{wb}}^{\prime \prime}$ is the heat flux that remains in the workpiece, which is assumed to be evenly distributed over the entire workpiece surface, and $q_{\mathrm{f}}^{\prime \prime}$ is the heat flux into the fluid, assumed to be uniform over the area exposed to the fluid.

To simplify the analysis it is assumed that: (a) the grinding zone is a two-dimensional region; (b) the system is under steady-state conditions; (c) the heat flux conducted into the chips, the abrasives, the workpiece, and the coolant fluid during grinding is uniform and constant; (d) the thermal properties of the system are constant; (e) conduction in the direction of motion is neglected. With these assumptions, the energy equation for the abrasive grit of the wheel, the workpiece, and the grinding fluid can be written as, respectively,

$V_{\mathrm{g}} \frac{\partial T_{\mathrm{g}}}{\partial x}=\alpha_{\mathrm{g}} \frac{\partial^{2} T_{\mathrm{g}}}{\partial z^{2}}$

$V_{\mathrm{w}} \frac{\partial T_{\mathrm{w}}}{\partial x}=\alpha_{\mathrm{w}} \frac{\partial^{2} T_{\mathrm{w}}}{\partial z^{2}}$

$V_{\mathrm{f}} \frac{\partial T_{\mathrm{f}}}{\partial x}=\alpha_{\mathrm{f}} \frac{\partial^{2} T_{\mathrm{f}}}{\partial z^{2}}$

\subsection{Heat transfer to the wheel abrasive grains, the workpiece, and the grinding fluid}

In this section the convection heat-transfer coefficients of the wheel grit, the workpiece, and the grinding fluid during grinding will be presented. The boundary conditions of the wheel grit for $T(x, z)$ are

$$
\begin{aligned}
T_{\mathrm{g}}(0, z)=T_{\mathrm{g}, \mathrm{i}} & =T_{\infty}, \quad-\left.k_{\mathrm{g}} \frac{\partial T_{\mathrm{g}}}{\partial z}\right|_{z=0}=q_{\mathrm{g}}^{\prime \prime}, \\
T_{\mathrm{g}}(x, \infty) & =\text { finite }
\end{aligned}
$$

The solution to the differential equation (1a) and the boundary conditions (2), in dimensionless form, is the well-known error function, which can be expressed as

$\Theta_{\mathrm{g}}=2\left(\frac{X_{\mathrm{g}}}{\pi}\right)^{1 / 2} \exp \left(\frac{-Z_{\mathrm{g}}^{2}}{4 X_{\mathrm{g}}}\right)-Z_{\mathrm{g}} \operatorname{erfc}\left(\frac{Z_{\mathrm{g}}}{2 X_{\mathrm{g}}^{1 / 2}}\right)$

where the dimensionless quantities are defined as $\Theta_{\mathrm{g}}=\left(T_{\mathrm{g}}-T_{\mathrm{g}, \mathrm{i}}\right) /\left(q_{\mathrm{g}} /\left(\rho c_{p} V\right)_{\mathrm{g}}\right), X_{\mathrm{g}}=(x V / \alpha)_{\mathrm{g}}$, and $Z_{\mathrm{g}}=(z V / \alpha)_{\mathrm{g}}$. The local surface temperature $(z=0)$ of the wheel grain is

$\Theta_{\mathrm{g}, \mathrm{s}}=2\left(\frac{X_{\mathrm{g}}}{\pi}\right)^{1 / 2}$

The local convective heat-transfer coefficient of the wheel abrasives is

$h_{\mathrm{g}}=\frac{q_{\mathrm{g}}^{\prime \prime}}{T_{\mathrm{g}, \mathrm{s}}-T_{\mathrm{g}, \mathrm{i}}}=\left[\frac{\pi\left(k \rho c_{p} V\right)_{\mathrm{g}}}{4 x}\right]^{1 / 2}$

In addition, the thermal boundary layer thickness can be defined as the distance from the surface at which the temperature rise is $1 \%$ of the surface temperature rise, i.e., $\Theta / \Theta_{\mathrm{s}}=0.01$. From Eqs. (3) and (4), this occurs at $Z / 2 X^{1 / 2}=1.605$, or $\delta_{\mathrm{t}}=3.21\left(\alpha x / V_{\mathrm{g}}\right)^{1 / 2}$.

In a manner similar to that described above, the local convection heat-transfer coefficient corresponding to the workpiece background temperature is

$h_{\mathrm{wb}}=\frac{q_{\mathrm{w}}^{\prime \prime}}{T_{\mathrm{w}, \mathrm{s}}-T_{\mathrm{w}, \mathrm{i}}}=\left[\frac{\pi\left(k \rho c_{p} V\right)_{\mathrm{w}}}{4 x}\right]^{1 / 2}$

The heat transferred into the coolant fluid is mainly from the workpiece surface. The coolant fluid during grinding will be assumed to remain liquid. The moving velocity of the coolant fluid in the grinding zone is assumed to be approximately that of the surface peripheral speed of the wheel $\left(V_{\mathrm{f}}=V_{\mathrm{g}}\right)$. Hence, the local convective heat-transfer coefficient for the coolant fluid can be expressed similarly as

$h_{\mathrm{f}}=\frac{q_{\mathrm{f}}^{\prime \prime}}{T_{\mathrm{f}, \mathrm{s}}-T_{\mathrm{f}, \mathrm{i}}}=\left[\frac{\pi\left(k \rho c_{p} V\right)_{\mathrm{f}}}{4 x}\right]^{1 / 2}$ 
2.2. Energy of the shear plane between the workpiece and the chip

The energy of chip formation during grinding, $q_{\mathrm{sh}}^{\prime \prime}$, is conducted into the chip, $q_{\mathrm{c}}^{\prime \prime}$, and the workpiece and the wheel, $q_{\mathrm{ws}}^{\prime \prime}$. Hence, it can be expressed as

$q_{\mathrm{sh}}^{\prime \prime}=q_{\mathrm{c}}^{\prime \prime}+q_{\mathrm{ws}}^{\prime \prime}$

For the temperature $T_{\mathrm{sh}}(\xi)$ on the shear plane and the temperature $T_{\mathrm{w}, \mathrm{s}}$ at the contact point $\mathrm{S}$ between the chip and the workpiece (see Fig. 3), the energy equation for heat conducted into the chip can be expressed as

$\bar{T}_{\mathrm{sh}}-T_{\mathrm{w}, \mathrm{s}}=\frac{q_{\mathrm{c}}^{\prime \prime}}{h_{\mathrm{c}}}$

where

$h_{\mathrm{c}}=\frac{\left(\rho c_{p}\right)_{\mathrm{w}} t_{\mathrm{c}} V_{\mathrm{g}}}{l_{\mathrm{sh}}}$

The average undeformed chip thickness, $t_{\mathrm{c}}$, during grinding can be expressed as $[1,14]$

$t_{\mathrm{c}}=\left[\frac{V_{\mathrm{w}}}{V_{\mathrm{g}} n r \sqrt{d / D}}\right]^{1 / 2}$

where $n$ is the number of abrasive grits per unit area, $r\left(=b^{\prime} / t_{\mathrm{c}}\right)$ the ratio of the average chip width $b^{\prime}$ and the average chip thickness $t_{\mathrm{c}}$. The length of the shear plane $l_{\mathrm{sh}}$ is $t_{\mathrm{c}} / \sin \phi$.

The parameter $n$ in Eq. (11) can be determined from the experiment, its variation with the wheel grade being shown in Fig. 4 [15]. Further, the shear angle $\phi$ in orthogonal cutting is about $5^{\circ}[15]$.

The remaining energy $q_{\mathrm{ws}}^{\prime \prime}$ will be assumed to be conducted into the workpiece, its heat-transfer relationship being

$\bar{T}_{\mathrm{sh}}-T_{\mathrm{ws}, \mathrm{s}}=\frac{q_{\mathrm{ws}}^{\prime \prime}}{h_{\mathrm{ws}}}$

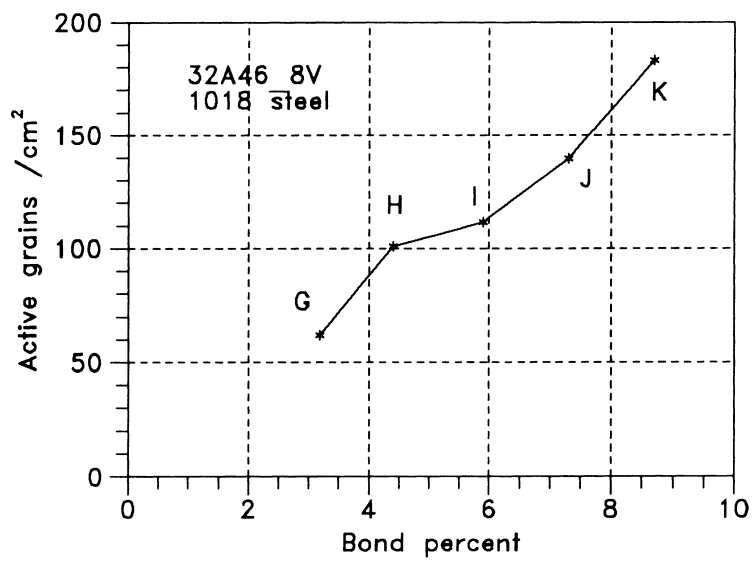

Fig. 4. Variation of the number of abrasive grains per unit area with the wheel grade [15]. where

$h_{\mathrm{ws}}=\left[\frac{\pi\left(k \rho c_{p} V\right)_{\mathrm{g}}}{l_{\mathrm{sh}}}\right]^{1 / 2}$

The average temperature $\bar{T}_{\text {sh }}$ (Eq. (9)) on the shear plane must be equal to the temperature on the shear plane of the chip (Eq. (12)):

$\frac{q_{\mathrm{ws}}^{\prime \prime}}{h_{\mathrm{ws}}}=\frac{q_{\mathrm{c}}^{\prime \prime}}{h_{\mathrm{c}}}$

Solving Eqs. (8) and (14) yields

$q_{\mathrm{c}}^{\prime \prime}=\frac{q_{\mathrm{sh}}^{\prime \prime}}{1+h_{\mathrm{ws}} / h_{\mathrm{c}}}$

Generally, the abrasive shape of the wheel is irregular. However, the abrasive during grinding will be modeled as a cone, so that the contact cross-sectional area between the grit and the workpiece is a circle. The projected area of the shear plane will be assumed as a shape that is between that of a semi-ellipse and that of a semi-circle, its schematic illustration being shown in Fig. 5. Hence, the area of the shear plane produced by each active abrasive is

$a_{\mathrm{sh}}=\frac{\pi r_{0} l_{\mathrm{sh}}}{2}$

where $r_{0}=\left(A_{\mathrm{g}} / n \pi A_{\text {total }}\right)^{1 / 2}, A_{\mathrm{g}}$ is the wear flat area of the abrasive in the grinding zone, and $A_{\text {total }}$ the area of the grinding zone.

When the chip is formed during grinding, its heat-transfer rate per unit area on the shear plane is given by $[1,16]$

$q_{\mathrm{sh}}^{\prime \prime}=u_{\mathrm{sh}} V_{\mathrm{g}} \sin \phi$

where $u_{\mathrm{sh}}$ is the specific chip formation energy. Malkin and Anderson [8] indicated that $u_{\mathrm{sh}}$ obtained from the experiment is about $13.79 \mathrm{~J} / \mathrm{mm}^{2}$.

The total energy, $q_{\mathrm{sh}}$, of the chip formation in the overall grinding zone can be expressed as

$q_{\mathrm{sh}}=A_{\mathrm{sh}} q_{\mathrm{sh}}^{\prime \prime}=\frac{\pi n r_{0} t_{\mathrm{c}} u_{\mathrm{sh}} V_{\mathrm{g}} A_{\mathrm{total}}}{2}$

Hence, the heat flux, $q_{\mathrm{c}}^{\prime \prime}$, conducted into the chip can be solved by Eq. (15).

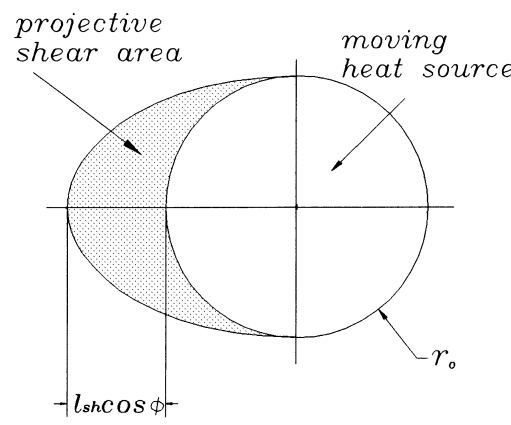

Fig. 5. Schematic illustration of the projected area of the shear plane. 


\subsection{Workpiece temperature rise}

The workpiece surface temperature rise, $\theta$, beneath the grain location is calculated as an uniform band heat source, $q_{\mathrm{wg}}^{\prime \prime}$, on the surface of a moving semi-infinite body, and can be written as $[16,17]$

$\theta(0, t)=\left(\frac{2 q_{\mathrm{wg}}^{\prime \prime}}{k_{\mathrm{w}}}\right)\left(\frac{\alpha_{\mathrm{w}} t}{\pi}\right)^{1 / 2}$

where $\theta$ is the temperature rise relative to the workpiece background temperature.

From Eq. (19), it can be found that the workpiece surface temperature rise is proportional to $t^{1 / 2}$. In other words, $\theta$ is proportional to the square root of the distance from the beginning of the grinding zone. The average surface temperature of the workpiece at the grain location, $\bar{\theta}_{\mathrm{wg}}$, can be calculated over the heat source area (a circular area)

$\bar{\theta}_{\mathrm{wg}}=\frac{0.9734 q_{\mathrm{wg}}^{\prime \prime} r_{0}^{1 / 2}}{\left[\left(k \rho c_{p}\right)_{\mathrm{w}} V_{\mathrm{g}}\right]^{1 / 2}}$

where $r_{0}$ is the radius of the individual grain heat source. Hence, the average convective heat-transfer coefficient of the workpiece under the individual grain is

$\bar{h}_{\mathrm{wg}}=\frac{q_{\mathrm{wg}}^{\prime \prime}}{\bar{\theta}_{\mathrm{wg}}}=1.0273\left[\frac{\left(k \rho c_{p}\right)_{\mathrm{w}} V_{\mathrm{g}}}{r_{0}}\right]^{1 / 2}$

\subsection{Coupling of the models}

Now the models for the wheel, the fluid, and the workpiece will be coupled, by requiring that the surface temperatures match. It has been assumed that the ambient temperature is the same for the wheel, the fluid, and the workpiece. Hence, when the abrasive grains do not contact the workpiece surface during grinding, then the workpiece surface temperature, $\theta_{\mathrm{wb}}$, must equal the fluid temperature rise, $\theta_{\mathrm{f}}$ :

$\theta_{\mathrm{f}}=\theta_{\mathrm{wb}} \Rightarrow \frac{q_{\mathrm{f}}^{\prime \prime}}{h_{\mathrm{f}}(x)}=\frac{q_{\mathrm{wb}}^{\prime \prime}}{h_{\mathrm{wb}}(x)}$

In addition, when the grains of the wheel during grinding contact the workpiece surface, then the grain temperature rise, $\theta_{\mathrm{g}}$, must equal the sum of the workpiece surface temperature, $\theta_{\mathrm{wb}}$, and the workpiece temperature rise, $\bar{\theta}_{\mathrm{wg}}$, due to an individual grain is

$\theta_{\mathrm{g}}=\theta_{\mathrm{wb}}+\bar{\theta}_{\mathrm{wg}} \Rightarrow \frac{q_{\mathrm{g}}^{\prime \prime}}{h_{\mathrm{g}}(x)}=\frac{q_{\mathrm{wb}}^{\prime \prime}}{h_{\mathrm{wb}}(x)}+\frac{q_{\mathrm{wg}}^{\prime \prime}}{\bar{h}_{\mathrm{wg}}}$

There are two additional relationships between the unknown heat fluxes, that were given earlier, namely:

$q_{\mathrm{wg}}^{\prime \prime} A_{\mathrm{g}}=q_{\mathrm{wb}}^{\prime \prime} A_{\text {total }}+q_{\mathrm{f}}^{\prime \prime} A_{\mathrm{f}}$

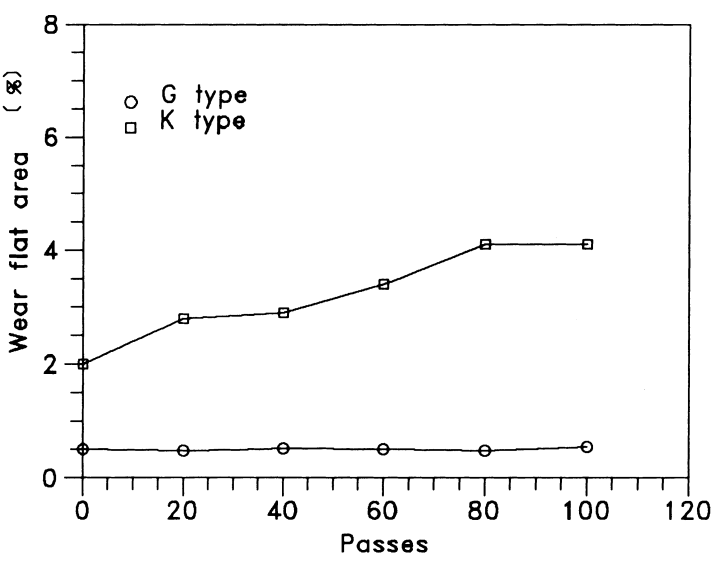

Fig. 6. Variation of the wear flat area of the abrasive with grinding passes for a grain size of US mesh 46 [15].

$q_{\mathrm{wf}}^{\prime \prime}=q_{\mathrm{g}}^{\prime \prime}+q_{\mathrm{wg}}^{\prime \prime}$

where $A_{\mathrm{f}}=A_{\text {total }}-A_{\mathrm{g}}-A_{\mathrm{sh}}$, Malkin [15] indicated that the optical method can be used to measure the ratios $A_{\mathrm{g}} / A_{\text {total }}$, their values for a grain mesh size of 46 being shown in Fig. 6. Quantity $q_{\mathrm{wf}}^{\prime \prime}$, which was given earlier, is equal to $q_{\text {total }}^{\prime \prime}-q_{\mathrm{c}}^{\prime \prime}$, where $q_{\text {total }}=F_{\mathrm{t}} V_{\mathrm{g}}$, whilst $F_{\mathrm{t}}$ for down cutting can be calculated from the following expression:

$F_{\mathrm{t}}=F_{\mathrm{h}} \cos \beta+F_{\mathrm{v}} \sin \beta$

where the horizontal force, $F_{\mathrm{h}}$, and the vertical force, $F_{\mathrm{v}}$, during grinding can be measured by a dynamometer during the experiment. $\beta(=\sqrt{d / D})$ is the angle between the middle line of the grinding zone and the vertical line through the wheel center. Hence $q_{\mathrm{wf}}$ can be calculated in the test.

Now Eqs. (22), (23), (24a) and (24b) are the four equations that can be solved for the four unknown heat fluxes $\left(q_{\mathrm{wb}}^{\prime \prime}, q_{\mathrm{wg}}^{\prime \prime}, q_{\mathrm{f}}^{\prime \prime}, q_{\mathrm{g}}^{\prime \prime}\right)$. Then the four temperature rises $\left(\theta_{\mathrm{wb}}, \bar{\theta}_{\mathrm{wg}}, \theta_{\mathrm{f}}, \theta_{\mathrm{g}}\right)$ are also known. An inconsistency now arises. All of the heat fluxes were taken to be uniform, Eq. (23) cannot be satisfied, because the two sides of the equation do not have the same $x$-dependence. Some or all of the heat fluxes must depend on $x$. Hence, an approximate method for handling this problem was the modification that $q_{\mathrm{g}}^{\prime \prime}$ varies with $x$, so that $q_{\mathrm{wf}}^{\prime \prime}$ must vary with $x$ as well [12]. Finally, in Eq. (23), $q_{\mathrm{g}}^{\prime \prime}$ will be replaced by $q_{\mathrm{g}}^{\prime \prime}(x)$, and Eq. (24b) will be modified as an integrated form

$q_{\mathrm{wf}}=\int_{A_{\mathrm{g}}} q_{\mathrm{wf}}^{\prime \prime}(x) \mathrm{d} A_{\mathrm{g}}=q_{\mathrm{wg}}^{\prime \prime} A_{\mathrm{g}}+\frac{A_{\mathrm{g}}}{A_{\text {total }}} \int_{0}^{l} q_{\mathrm{g}}^{\prime \prime}(x) b \mathrm{~d} x$

Eqs. (22), (23) and (24a) can be used to express $q_{\mathrm{g}}^{\prime \prime}(x)$ and $q_{\mathrm{wg}}^{\prime \prime}$ in terms of $q_{\mathrm{wb}}^{\prime \prime}$, and the results can be substituted into Eq. (26) to yield the following equation for $q_{\mathrm{wb}}^{\prime \prime}$ :

$q_{\mathrm{wb}}^{\prime \prime}=\frac{q_{\text {total }}^{\prime \prime}(1-M)}{1+\left(h_{\mathrm{f}}(x) / h_{\mathrm{wb}}(x)\right)\left(A_{\mathrm{f}} / A_{\text {total }}\right)+\left(\mathrm{A}_{\mathrm{g}} / l A_{\text {total }}\right) \int_{0}^{l}\left[\left(h_{\mathrm{g}}(x) / h_{\mathrm{wb}}(x)\right)+\left(h_{\mathrm{g}}(x) / \bar{h}_{\mathrm{wg}}\right)\left(\left(A_{\text {total }} / A_{\mathrm{g}}\right)+\left(h_{\mathrm{f}}(x) / h_{\mathrm{wb}}(x)\right)\left(A_{\mathrm{f}} / A_{\mathrm{g}}\right)\right)\right] \mathrm{d} x}$ 
where $M=q_{\mathrm{c}} / q_{\text {total }}$.

Hence, the surface temperature rise of the workpiece, $\theta_{\mathrm{wb}}$, is given by
The wheel peripheral speed, $V_{\mathrm{g}}$, during grinding was kept at $21 \mathrm{~m} / \mathrm{s}$. The stroke of the table of the surface grinder is $130 \mathrm{~mm}$.

$\theta_{\mathrm{wb}}(x)=\frac{\left(q_{\text {total }}^{\prime \prime} / h_{\mathrm{wb}}(x)\right)(1-M)}{1+\left(h_{\mathrm{f}}(x) / h_{\mathrm{wb}}(x)\right)\left(A_{\mathrm{f}} / A_{\text {total }}\right)+\left(A_{\mathrm{g}} / l A_{\text {total }}\right) \int_{0}^{l}\left[\left(h_{\mathrm{g}}(x) / h_{\mathrm{wb}}(x)\right)+\left(h_{\mathrm{g}}(x) / \bar{h}_{\mathrm{wg}}\right)\left(\left(A_{\mathrm{total}} / A_{\mathrm{g}}\right)+\left(h_{\mathrm{f}}(x) / h_{\mathrm{wb}}(x)\right)\left(A_{\mathrm{f}} / A_{\mathrm{g}}\right)\right)\right] \mathrm{d} x}$

where $\theta_{\mathrm{wb}}(x)$ is any workpiece surface temperature at the grinding zone. Hence, when the grinding conditions are known, the workpiece surface temperature can be predicted by means of Eq. (28). Generally, the temperature measured by the thermocouple in the wet grinding process may be the maximum workpiece surface temperature. It is equivalent to the temperature at the end of the grinding zone, $x=l$. The temperature, $\theta_{\mathrm{wb} \text {,max }}$, will govern the thermal damage to the workpiece during grinding.

\section{Experimental procedures}

The experimental grinding device is shown in Fig. 7. The grinding fluid is pressurized and regulated through a pump and a valve, and its flow rate is measured by a flow-meter. The fluid passes through the nozzle into the wheel surface periphery and, thereafter, is collected through the flow channel to the container.

Tests were conducted with a down-grinding and a plunge condition. The grinding wheel specification used in the test is WA60K8V, and its size is $180 \mathrm{~mm} \times 19 \mathrm{~mm} \times 31.75 \mathrm{~mm}$. The workpiece material is AISI 1045, and its size used is $100 \mathrm{~mm} \times 50 \mathrm{~mm} \times 19 \mathrm{~mm}$.
The horizontal and vertical grinding force components $F_{\mathrm{h}}$ and $F_{\mathrm{v}}$ were measured by means of a quartz piezoelectric type dynamometer (Kistler type 9257B) connected to an $\mathrm{A} / \mathrm{D}$ converter and a personal computer.

The useful flow rate, $\dot{Q}_{\text {c,useful }}$, during grinding was defined as the ratio between the fluid volume that flowed into the grinding zone and the contact time of the wheel and workpiece.

\section{Results and discussion}

\subsection{Evaluation of the thermal boundary layer thickness and the grinding fluid thickness}

The fluid observed on the wheel surface during grinding forms the two regions R1 and R2 as shown in Fig. 8. The amount of the fluid flowing into the grinding zone in the test is shown in Fig. 9a and b. It can be found that the useful flow rate of the fluid is linearly proportional to the total flow rate, and it is not influenced by the depth of cut and table speed. However, the useful flow rate in a lower total flow rate would have an offset. This may be that the momentum of the fluid in region $\mathrm{R} 2$ cannot resist the air film of the grinding wheel due to the wheel rotation.

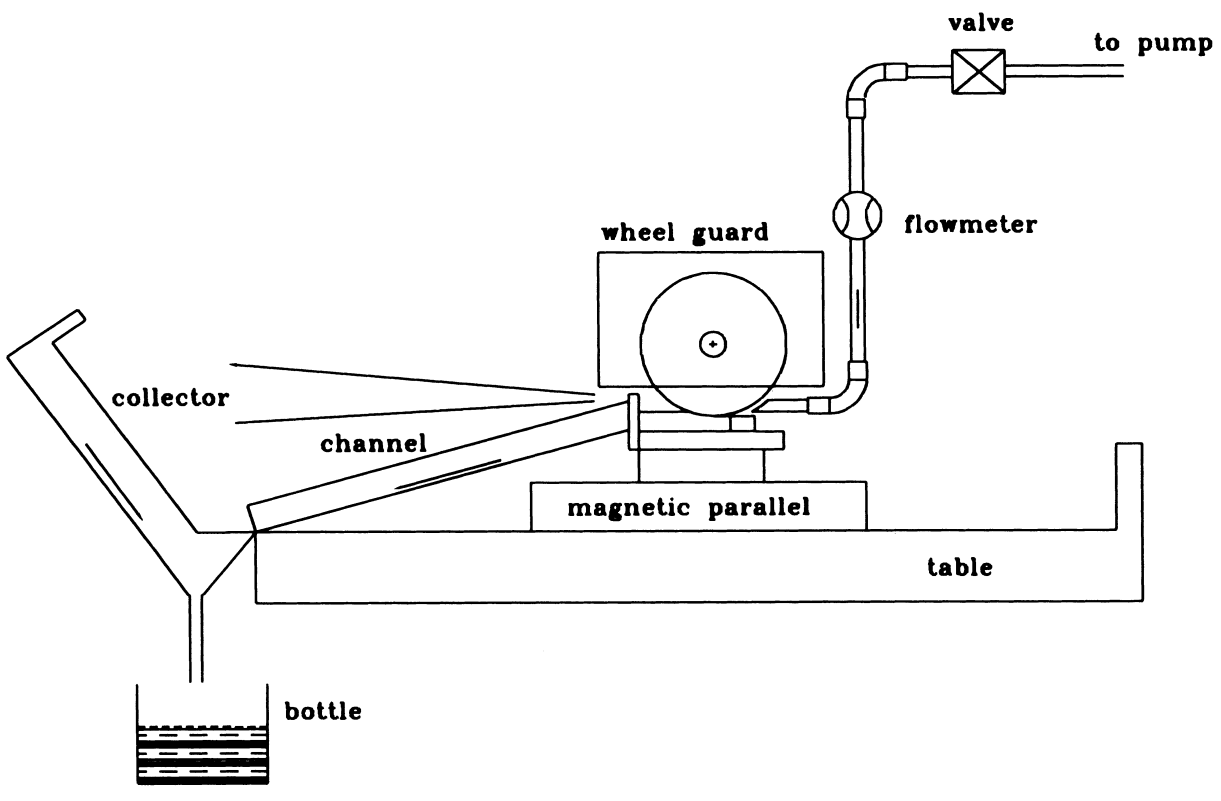

Fig. 7. Experimental setup. 


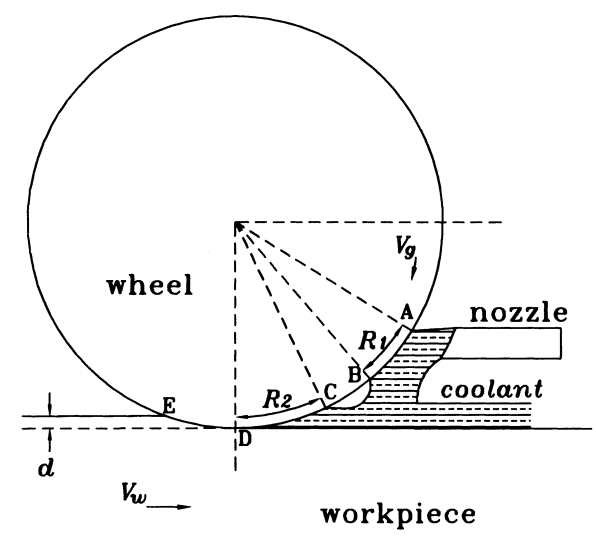

Fig. 8. Distribution of the fluid observed on the wheel surface during grinding.

If the relative velocity of the fluid to the wheel is assumed to be zero, then the fluid with the wheel speed, $V_{\mathrm{g}}$, would flow into the grinding zone. Further, the effective wheel porosity $\phi_{\mathrm{s}}$ of the contact zone between the wheel and the workpiece is larger than the bulk wheel porosity $\phi_{\mathrm{b}}$. Hence, their ratio can be expressed as a dimensionless parameter $\Phi$, its form being
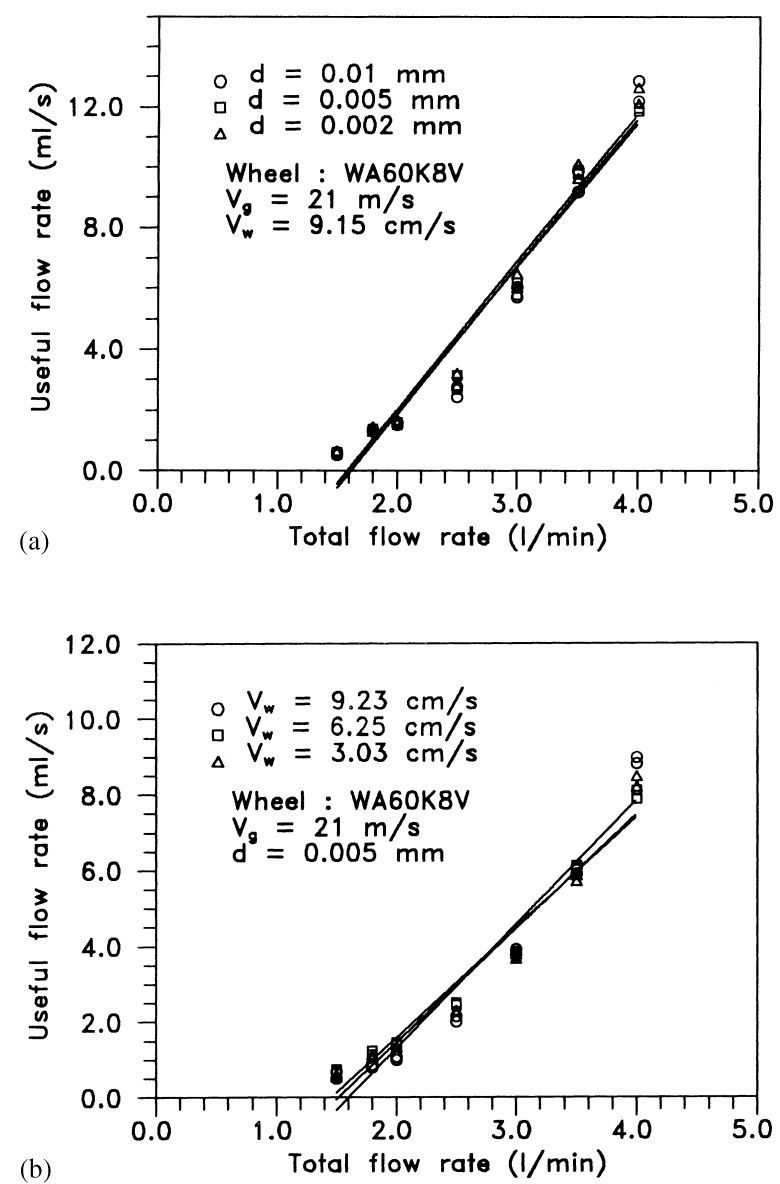

Fig. 9. The useful flow rate of the fluid versus the total flow rate for: (a) depth of cut $d$; and (b) table speed $V_{\mathrm{w}}$.
Table 1

Porosity of the grinding wheel [17]

\begin{tabular}{llll}
\hline Wheel & $\begin{array}{l}\text { Bulk porosity } \\
\phi_{\mathrm{b}}(\%)\end{array}$ & $\begin{array}{l}\text { Effective porosity } \\
\phi_{\mathrm{s}}(\%)\end{array}$ & $\begin{array}{l}\text { Parameter } \\
\Phi\end{array}$ \\
\hline 38A60K8VBE & 43.2 & 47.0 & 1.09 \\
38A60I8VBE & 46.0 & 58.0 & 1.26 \\
38A60I25VCF2 & 51.5 & 93.0 & 1.81 \\
38A60F16VCF2 & 52.8 & 94.0 & 1.78 \\
\hline
\end{tabular}

$\phi_{\mathrm{s}}=\phi_{\mathrm{b}} \Phi$

where parameter $\Phi$ would vary with the grinding wheel type: its value measured is shown in Table 1 [17]. In addition, the average thickness of the fluid in grinding zone can be calculated as

$\delta_{\mathrm{f}}=\frac{\dot{Q}_{\mathrm{c}, \text { useful }}}{V_{\mathrm{g}} b \phi_{\mathrm{s}}}$

where $\dot{Q}_{\text {c,useful }}$ is the useful flow rate.

The thermal boundary layer thickness, $\delta_{t}$, of the fluid (see Section 2.1) and the average thickness, $\delta_{\mathrm{f}}$, of the fluid in the grinding zone under a total flow rate of $41 / \mathrm{min}$ and a useful flow rate of $10 \mathrm{l} / \mathrm{min}$ in the test are given in Table 2. It can be seen that the average thickness of the fluid covering the grinding zone is larger than the thermal boundary layer thickness. In practice, the total flow used during grinding is generally about $10-30 \mathrm{l} / \mathrm{min}$. Hence, it can be deduced that the fluid thickness, $\delta_{\mathrm{f}}$, in grinding zone must be generally larger than the thermal boundary layer thickness $\delta_{\mathrm{t}, \mathrm{f}}$, so that the assumption of the boundary condition $T(x, \infty)=$ finite of the fluid in Eq. (2) is satisfied.

In addition, Table 3 shows the results of the thermal boundary layer thickness of the abrasive grain and the abrasive size (US mesh 46). It can be seen that the abrasive grain diameter is also larger than $\delta_{\mathrm{t} \text { max }}$, then the boundary condition $T(x, \infty)=$ finite of Eq. (2) can also be satisfied. However, the thermal boundary layer thickness under the depth of cut of $1.0 \mathrm{~mm}$ is larger than the abrasive grain size, which shows that when the depth of cut during grinding is larger than $1 \mathrm{~mm}$, the wheel bond would influence the prediction model of the temperature.

Table 2

Results of the thermal boundary layer thickness, $\delta_{\mathrm{t}}$, of the fluid and the average thickness, $\delta_{\mathrm{f}}$, of the fluid ${ }^{\mathrm{a}}$

\begin{tabular}{lccc}
\hline $\begin{array}{l}\text { Depth of cut, } \\
d(\mathrm{~mm})\end{array}$ & $l(\mathrm{~mm})$ & $\begin{array}{l}\delta_{\mathrm{t}, \max } \text { of the } \\
\text { fluid }(\mathrm{mm})\end{array}$ & $\delta_{\mathrm{f}}(\mathrm{mm})$ \\
\hline 0.05 & 3.2 & 0.0156 & 0.0532 \\
0.5 & 12.25 & 0.0306 & 0.0528 \\
1.0 & 17.35 & 0.0364 & 0.0528 \\
\hline \multicolumn{2}{c}{${ }^{\mathrm{a}}$ Conventional grinding: $d=0.05 \mathrm{~mm}, D=205 \mathrm{~mm}, \dot{Q}_{\mathrm{c}, \mathrm{useful}}=10 \mathrm{ml} / \mathrm{s}}$, \\
$\phi_{\mathrm{s}}=0.47 ;$ creep-feed grinding: $d=0.5$ and $1.0 \mathrm{~mm}, \quad D=300 \mathrm{~mm}$, \\
$\begin{array}{l}\dot{Q}_{\mathrm{c}, \text { useful }}=20 \mathrm{ml} / \mathrm{s}, \phi_{\mathrm{s}}=0.95 . \\
{ }_{\mathrm{b}} \mathrm{V}_{\mathrm{g}}=21 \mathrm{~m} / \mathrm{s}, b=19 \mathrm{~mm} .\end{array}$
\end{tabular}


Table 3

Results of the thermal boundary layer thickness, $\delta_{\mathrm{t}}$, of the abrasive and grain size of US mesh $46^{\mathrm{a}}$

\begin{tabular}{lcll}
\hline $\begin{array}{l}\text { Depth of cut, } \\
d(\mathrm{~mm})\end{array}$ & $l(\mathrm{~mm})$ & $\begin{array}{l}\delta_{\mathrm{t}, \max } \text { of the } \\
\text { abrasive }(\mathrm{mm})\end{array}$ & $\begin{array}{l}\text { Grain size (US } \\
\text { mesh 46) }(\mathrm{mm})\end{array}$ \\
\hline 0.05 & 3.2 & 0.157 & 0.35 \\
0.5 & 12.25 & 0.307 & 0.35 \\
1.0 & 17.35 & 0.365 & 0.35 \\
\hline
\end{tabular}

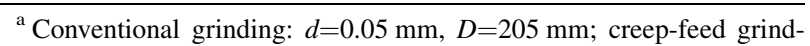
ing: $d=0.5$ and $1.0 \mathrm{~mm}, D=300 \mathrm{~mm}$.

${ }^{\mathrm{b}} V_{\mathrm{g}}=21 \mathrm{~m} / \mathrm{s}$.

\subsection{Comparison between the predicted value and the experimental value}

\subsubsection{For conventional grinding}

The predicted results of the model will be compared to the experimental data for conventional grinding. The data are given by Yasui and Tsukuda [3], the grinding conditions and the thermal properties of the materials being given in Tables 4 and 5, respectively. The flow rate of the grinding fluid is $15 \mathrm{l} / \mathrm{min}$. The theoretical predictions given by Eq. (28) and Lavine and Jen [12], and the experimental results are shown in Fig. 10a. It can be seen that the influence of the heat source of the shear plane on the temperature of the grinding zone is not very significant. The maximum temperature rise predicted for soluble grinding fluid is greater than that of the experiment. However, the predicted temperatures for oilbased grinding fluid are smaller than those of the experiment. The reason for this may be the result of the different coolant rates of various fluids. If the variation of the thermal conductivity of the grinding fluids with temperature is modified, then the theoretical predictions will provide better results. For water-based coolant, the error is reduced under $10^{\circ} \mathrm{C}$ (see symbol $\triangle$ of Fig. 10a). However, the error of the predictions for oil-based grinding fluid at higher temperatures is still a little large (see symbol $\diamond$ of Fig. 10a). This may be because the thermal properties of the workpiece are not modified.

\subsubsection{For creep grinding}

The results of the model will be compared to experimental data for creep grinding. The experimental data are given by Ohishi and Furukawa [4], and the grinding conditions are

Table 4

Operating conditions

\begin{tabular}{lll}
\hline Grinding type & Conventional grinding & Creep-feed grinding \\
\hline Grinding mode & Down cutting & Down cutting \\
Grinding wheel & WA46K8V & WA46G8V \\
Wheel size & $\varnothing 205 \mathrm{~mm} \times 19 \mathrm{~mm}$ & $\varnothing 300 \mathrm{~mm} \times 19 \mathrm{~mm}$ \\
& $\times 50 \mathrm{~mm}$ & $\times 50 \mathrm{~mm}$ \\
Workpiece & SKD11 tool steel & SUJ 2 \\
Depth of cut, $d$ & $0.05 \mathrm{~mm}$ & $0.5,1.0 \mathrm{~mm}$ \\
Wheel speed, $V_{\mathrm{g}}$ & $20 \mathrm{~m} / \mathrm{s}$ & $18 \mathrm{~m} / \mathrm{s}$ \\
Table speed, $V_{\mathrm{w}}$ & $33 \mathrm{~m} / \mathrm{s}$ & $1.2 \mathrm{~mm} / \mathrm{s}$ \\
\hline
\end{tabular}

Table 5

Material properties

\begin{tabular}{llcclrr}
\hline & Unit & Water & \multicolumn{1}{l}{ Oil } & Air & $\mathrm{Al}_{2} \mathrm{O}_{3}$ & Steel \\
\hline$k$ & $\mathrm{~W} / \mathrm{m} \mathrm{K}^{3}$ & 0.65 & 0.15 & 0.02624 & 46 & 60.5 \\
$\rho$ & $\mathrm{kg} / \mathrm{m}^{3}$ & 1000 & 820 & 1.1774 & 4000 & 7854 \\
$c_{p}$ & $\mathrm{~J} / \mathrm{kg}^{\circ} \mathrm{C}$ & 4180 & 2000 & 1.0057 & 770 & 434 \\
\hline
\end{tabular}

shown in Table 4. The flow rate of the coolant is $25 \mathrm{l} / \mathrm{min}$. The theoretical predictions given by Eq. (28) and Lavine and Jen [12], and the experimental results are shown in Fig. 10b. It can be seen that the maximum temperature rise predicted for soluble grinding fluid is larger than that of the experiment. This may be due to the following factors: (i) The contact length of the grinding zone of the wheel for creep grinding is larger than that for conventional grinding. Hence, the contact time between the grinding fluid and the workpiece is longer. This will cause a large amount of heat to be dissipated. When the heat flux $q_{\text {total }}^{\prime \prime}$ of the grinding zone is increased, the temperature of the grinding zone would be increased and the temperature of the fluid is also increased. The effect of heat transfer of the grinding fluid increases with the increase in temperature. Thus, the heat-transfer coefficient of the fluid at a higher temperature is larger than
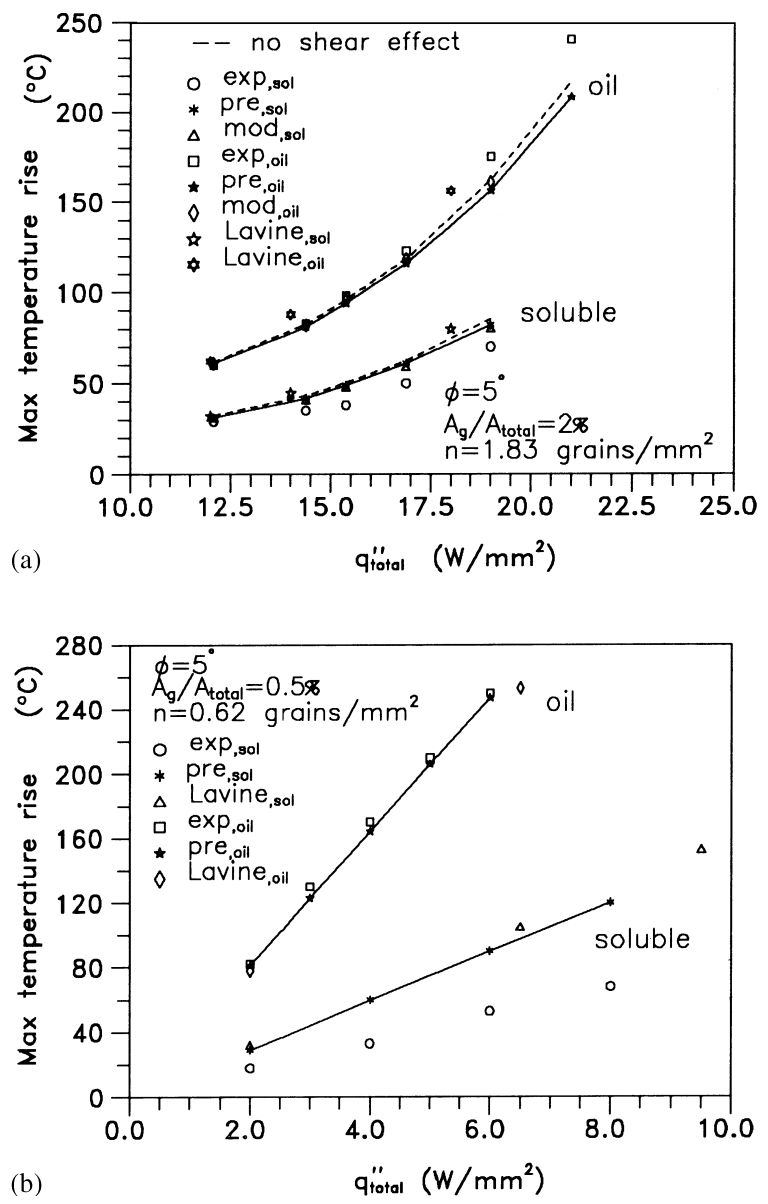

Fig. 10. Maximum temperature rise of the theoretical predictions for: (a) conventional grinding; and (b) creep-feed grinding. 
the assumed values of the model. (ii) The table speed in creep grinding is lower, so that conduction in the $x$-direction of motion during creep grinding should be considered. However, the conductive heat transfer of the $x$-direction in the governing equation (1a) is neglected. These causes may lead to a larger theoretical prediction when using waterbased grinding fluid.

For oil-based grinding fluid, the theoretically predicted temperature is very close to the experimental data (see Fig. 10b). The reasons for this may be as follows: (i) The cooling rate of oil-based fluid is different with that of water-based fluid. (ii) The boundary condition $T_{\mathrm{g}, \mathrm{i}}$ of the wheel in Eq. (2) is considered as $T_{\infty}$, but the wheel during creep grinding retains practically a small amount of heat [12]. (iii) The viscosity of the oil-based fluid is larger than that of the water-based fluid. This would cause the oil-based fluid to remain on the wheel sub-surface. This oil film would re-cool the grinding zone to affect its heat transfer. These three factors may cause the conductive heat transfer in the $x$ direction during creep grinding to produce an inter-compensation effect. Hence, the agreement is seen to be excellent for oil-based fluid.

\section{Conclusions}

A simple thermal model of the wet grinding process has been used to predict the temperature of the workpiece surface. The model considers that the heat sources during grinding are from the abrasive grain/workpiece interface and the shear plane between the workpiece and chip. The experimental results show that the flow rate of the coolant under general grinding conditions are sufficient to cover the coolant thermal boundary layer in the grinding zone. The predicted workpiece surface temperature has been compared to experimental data for some grinding conditions. A good agreement is obtained except for the creep-feed grinding process when water-based grinding fluid is used. The difference between the theoretical values and experimental results are attributed to constant thermal properties, and neglect of transverse conduction in the development of the thermal model. In addition, the contribution of the heat source in the shear plane of the chip/workpiece interface on the workpiece surface temperature is comparatively less significant.

\section{References}

[1] J.O. Outwater, M.C. Shaw, Surface temperature in grinding, Trans. ASME 74 (1952) 73-86.

[2] R. Snoeys, M. Maris, J. Peters, Thermally induced damages in grinding, Ann. CIRP 27 (2) (1978) 571-581.

[3] H. Yasui, S. Tsukuda, Influence of fluid type on wet grinding temperature, Bull. Jpn. Soc. Prec. Eng. 17 (2) (1983) 133-134.

[4] S. Ohishi, Y. Furukawa, Analysis of workpiece temperature and grinding burn in creep feed grinding, Bull. JSME 28 (242) (1985) 1775-1781.

[5] J.C. Jaeger, Moving sources of heat and the temperature at sliding contacts, Proc. Soc. N. South Wales 76 (1942) 203-224.

[6] R.S. Hahn, The relation between grinding condition and thermal damage in the workpiece, Trans. ASME 78 (1956) 807-812.

[7] N.R. Des Ruisseaux, R.D. Zerkle, Thermal analysis of the grinding process, ASME J. Eng. Ind. 92 (1970) 428-434.

[8] S. Malkin, R.B. Anderson, Thermal aspects of grinding. Part 1. Energy partition, ASME J. Eng. Ind. 96 (1974) 1177-1183.

[9] S. Malkin, R.B. Anderson, Thermal aspects of grinding. Part 2. Surface temperatures and workpiece burn, ASME J. Eng. Ind. 96 (1974) 1184-1191

[10] N.R. Des Ruisseaux, R.D. Zerkle, Temperature in semi-infinite and cylindrical bodies subjected to moving sources and surface cooling, ASME J. Heat Transfer 92 (1970) 456-464.

[11] A.S. Lavine, A simple model for convective cooling during the grinding process, ASME J. Eng. Ind. 110 (1988) 1-6.

[12] A.S. Lavine, T.C. Jen, Thermal aspects of grinding: heat transfer to workpiece, wheel, and fluid, ASME J. Heat Transfer 113 (1991) 299_ 303.

[13] A.S. Lavine, T.C. Jen, Coupled heat transfer to workpiece, wheel, and fluid in grinding, and the occurrence of workpiece burn, Int. J. Heat Mass Transfer 34 (1991) 983-992.

[14] A.S. Lavine, Thermal aspects of grinding: the effect of heat generation at the shear planes, Ann. CIRP 40 (1) (1991) 343-345.

[15] S. Malkin, N.H. Cook, The wear of grinding wheels. Part 1. Attritious wear, ASME J. Eng. Ind. 93 (1971) 1120-1128.

[16] N.H. Cook, Manufacturing Analysis, Addison-Wesley, Reading, MA, 1966 (Chapter 3).

[17] C. Guo, S. Malkin, Analysis of fluid flow through the grinding zone, ASME J. Eng. Ind. 114 (1992) 427-434. 